\title{
Identificação e caracterização da tecnologia cafeeira e seus impactos no emprego e na mão de obra dos sistemas de produção.
}

\author{
Felipe Bellodi Bellini, Marco Túlio Ospina Patino.
}

\begin{abstract}
Resumo
Apesar de possibilitar a redução de custos e acelerar os processos, a adoção de novas tecnologias tem uma relação conflituosa com a geração e manutenção de empregos. Com o aumento da utilização de novos equipamentos e máquinas nas lavouras de café, esta pesquisa busca caracterizar a tecnologia e quantificar a geração de emprego da produção cafeeira da Mogiana Paulista no período de 2003 a 2017, região conhecida pela produção de cafés especiais. Foi realizado um levantamento de dados e informações em sites de órgãos governamentais, revistas, periódicos, livros e artigos científicos, caracterizando uma pesquisa exploratória, e utilizando a análise de componentes principais e a regresão linear múltipla como método de análise dos dados coletados. Os resultados indicam um aumento na mecanização da lavoura cafeeira da Mogiana Paulista, assim como mudanças nos salários, idade e diminuição na quantidade de mão de obra utilizada, relacionadas ao maior uso de máquinas.
\end{abstract}

\section{Palavras-chave:}

Tecnologia, sistemas de produção, geração de emprego.

\section{Introdução}

$\mathrm{Na}$ agropecuária brasileira, a inserção de novos aparatos tecnológicos e máquinas têm sido adotada como forma de facilitar e tornar os processos produtivos mais rápidos, diminuindo seus custos e aumentando seu rendimento. Porém, mesmo fornecendo vantagens competitivas, as novas tecnologias e a mecanização sempre tiveram uma relação conflituosa e complexa com a quantidade e a qualidade dos empregos. Um exemplo que explicita esse caso na agricultura brasileira é a implantação da colheita mecanizada da cana-de-açúcar, que destruiu empregos, mas criou novos de melhor remuneração e mais seguros. Este trabalho teve como objetivo a caracterização das tecnologias e a quantificação da geração de empregos da produção cafeeira na região da Mogiana Paulista, conhecida pelos seus cafés diferenciados.

\section{Resultados e Discussão}

A mecanização tem sido a principal estratégia competitiva dos produtores de café da Mogiana Paulista, reduzindo os custos e mantendo o mesmo rendimento. Segundo os dados dos Censos Agropecuários (IBGE) de 2006 e 2017, nos municípios da região onde o café representa mais de $5 \%$ da área plantada, houve um aumento de $44,98 \%$ no número de tratores e $65,98 \%$ no número de colheitadeiras. Nos mesmos anos, segundo dados da Relação Anual de Informações Sociais (RAIS), o número de trabalhadores de café diminuiu $60,75 \%$.

Para estudar a possível mudança de perfil dessa mãode-obra, devido a grande quantidade de variáveis, utilizou-se o software XLSTAT para a realização de uma análise de componentes principais (ACP). Pelos resultados obtidos (Tabela 1), observa-se que os 4 primeiros componentes explicam cerca de $72 \%$ da variação dos dados relacionados à produção e emprego na Mogiana Paulista, contribuindo com 48,9\%, 12,1\%, $5,8 \%$ e $5,3 \%$, respectivamente.

Tabela 1. Resultados dos 4 primeiros PC's.

\begin{tabular}{|l|l|l|l|l|}
\hline & PC1 & PC2 & PC3 & PC4 \\
\hline Eigenvalue & 13,679 & 3,389 & 1,613 & 1,480 \\
\hline Proportion & 0,489 & 0,121 & 0,058 & 0,053 \\
\hline Cumulative & 0,489 & 0,610 & 0,667 & 0,720 \\
\hline
\end{tabular}

Dentre os maiores coeficientes de correlação das variáveis com PC1 destacam-se a faixa salarial de 1.01 a 2.00 salários mínimos e a faixa etária de 50 a 64 anos. No segundo componente, as variáveis positivamente mais correlacionadas são a quantidade produzida e o valor da produção. Isso indica que esses PC's tenham sido caracterizados por essas variáveis.

Juntamente com a ACP, realizando regressões lineares múltiplas (RLM), observam-se coeficientes de regressão que indicam uma tendência de aumento salarial da mão de obra, passando da faixa de 1.00 a 2.00 salários mínimos para uma de 2.01 a 4.00 salários mínimos. Também nota-se a tendência de manter os funcionários mais velhos e experientes (de 50 a 64 anos), com o aumento gradual de uma mão-de-obra mais jovem (18 a 29 anos), mais capacitada e familiarizada com as novas tecnologias e com a operação de maquinários.

Além disso, a mecanização alterou a estrutura de custos das lavouras cafeeiras, como pode ser notado pelos dados obtidos da CONAB (2003 a 2018) na Tabela 2.

Tabela 2. Porcentagem de participação nos custos.

\begin{tabular}{|l|l|l|l|l|}
\hline & 2005 & 2010 & 2015 & 2018 \\
\hline Máquinas próprias & $6,1 \%$ & $5,0 \%$ & $2,7 \%$ & $6,7 \%$ \\
\hline Máquinas alugadas & $0,0 \%$ & $0,2 \%$ & $12,3 \%$ & $10,6 \%$ \\
\hline Mão-de-obra & $32,3 \%$ & $59,0 \%$ & $13,5 \%$ & $17,6 \%$ \\
\hline
\end{tabular}

\section{Conclusões}

No período de 2003 a 2018 a região produtora de cafés especiais, conhecida como Mogiana Paulista, apresentou diminuição de trabalhadores na lavoura de café, juntamente com aumento expressivo da utilização de tratores e colheitadeiras.

As análises realizadas indicam uma tendência para a mudança do perfil desses trabalhadores, sendo estes mais capacitados para as operações mecanizadas, com faixa etária menor e faixa salarial maior.

\section{Agradecimentos}

Agradeço ao CNPq e a PRP da UNICAMP, pelo incentivo e auxílio com a bolsa para o projeto. 